\title{
Integração e liberdade: uma reflexão histórica*
}

\author{
HUGO JAVIER GOBBI
}

\section{A origem do conceito integração política externa}

\section{A. A integração}

Provavelmente, as primeiras reflexões teóricas a respeito do processo de unificação de sociedades políticas independentes tenha se realizado na Grécia Antiga. É por isso que nós também seguiremos as recomendações de Bertrand Jouvenel $^{1}$ e viajaremos a Atenas para ver como se compreendeu, no mundo clássico, o fenômeno da integração política externa.

A viagem à antigüidade grega se justifica porque os gregos procederam muito rápido a uma tematização da vida política. Essa tematização surge de uma reflexão crítica tanto da experiência da Polis em sua vida interna como na relação da Polis com outras unidades políticas.

Veremos, então, como se compreendeu o conceito de integração política externa e quais foram suas conseqüências em dois momentos diferentes da antigüidade grega. Os dois casos que serão analisados não assinalam que o processo de integração permite uma troca que supera o aspecto meramente quantitativo da simples acumulação ou agrupamento de sociedades políticas independentes em um novo conjunto de maior tamanho. Em ambos os casos haverá, além do elemento quantitativo, um elemento qualitativo que transformará a natureza das unidades políticas que formam a nova entidade.

O primeiro caso de integração política externa permitiu o desenvolvimento da Polis grega através do processo que se denominou, nesse contexto: sinoecismo. Tal palavra descrevia a unificação de várias aldeias (komé) para fundar a cidade (Polis).

O uso de categorias modernas para entender as Polis gregas (como, por exemplo, cidades-Estados) resulta limitado em seu alcance. A Polis, que significava "Estado que se governa a si mesmo" ${ }^{2}$, era um termo intimamente ligado à autonomia da comunidade política.

A Polis, no mundo grego, era um local ou um espaço determinado, era "uma construção espiritual, um feito moral, religioso e político, antes que um conjunto arquitetural” . O exemplo de Atenas é ilustrativo, era uma capital administrativa e

* Traduzido do espanhol por Eric do Val Lacerda Sogocio. 
o centro religioso de uma sociedade política que se estendia para além dos muros da cidade. Os habitantes eram cidadãos atenienses ainda que vivessem fora da cidade de Atenas. Sem embargo, a dimensão constituía um fator importante de identificação de uma Polis, de sorte que não se compreendia como tal uma liga ou uma região.

Assim mesmo, a Polis encarnava uma realidade política, um programa social e religioso, que agrupava de maneira indissolúvel os homens, os deuses e o Estado em uma religião cívica ${ }^{4}$. Nesse sentido, constituía uma entidade de natureza totalitária, na qual o pertencimento e a participação no corpo político eram a própria essência da cidadania. Da Polis surgiam todos os direitos e obrigações dos cidadãos, sua autoridade cobria todas as esferas do comportamento humano. Os termos democracia, lei ou liberdade não têm a mesma concepção na atualidade.

A Polis não só refletia uma entidade política, constituía ela mesma um ideal e uma aspiração como se vê na própria descrição de Aristóteles: “a Polis é o espaço de debate e de reflexão onde os homens podem desenvolver suas virtudes essenciais" ${ }^{5}$.

Várias cidades gregas foram formadas pelo processo de sinoecismo, por exemplo: Atenas, Esparta e Megalópolis. Esta última foi a capital de Arcádia e reunia a população de quarenta aldeias. Sem embargo, o sinoecismo daquela época, assim como os processos de desintegração política ou de integração mais tarde, nunca são irreversíveis. Megalópolis nos dá um dos primeiros exemplos de integração política, este processo se chamava dioecismo, a cidade foi destruída e a população se dispersou em vários povoados.

B. A Lei. “O povo deve lutar pelas leis como a defender um último refúgio”6

Assim mesmo, houve em tal processo uma mudança de natureza que ia além do simples aspecto quantitativo. A integração de vários Komes para formar a Polis permite a construção de uma forma de organização social diferente. Talvez, a característica mais significativa da unificação de várias Komes para formar uma Polis foi a transformação da concepção da justiça e do direito.

A Polis refletia a aspiração revolucionária, a verdadeira obsessão pela justiça, do velho poeta Hesíodo: "Mais vale tomar o caminho que leva à justiça que finalmente triunfa sobre a desmesura"7.

Nas aldeias Komes as sentenças judiciais emanavam dos magistrados. Essas sentenças, chamadas Diké e Grafé, eram, respectivamente, sentenças privadas ou públicas. Os Diké entretanto, se diferenciavam de maneira essencial de nossa jurisprudência atual, ainda que a última também reflita a subjetividade pontual do magistrado, porque a jurisprudência atual é dependente de um marco normativo superior: a Lei. Como assinala Michel Schooyans, é precisamente esse marco de referência, a Lei, que falta na Diké tradicional. 
A existência da Lei (nomos) marca uma mudança de natureza da Polis com relação aos Komes porque as leis não são um mero compromisso ou acordo entre partes, são muito mais que um contrato: “a lei é obra da razão e aponta a encarnar um certo ideal de justiça" . $^{\circ}$

Um fato fundamental nesse processo foi a eleição como Magistrado (Arconte) do grande legislador ateniense Sólon, no ano de 594 antes de Cristo. Sólon, que viveu ente os anos 640 e 558 antes de Cristo, guiado pelo princípio da eunomia (ordem e medida) ${ }^{9}$, se transforma no árbitro equilibrado entre os interesses do povo e da nobreza em um contexto de forte agitação social.

Como assinala Rubén Bouchet, "Sólon não pertence a uma época em que a política se converte em objeto de reflexão teórica. Seus instintos e sua inteligência política atuavam sobre a realidade concreta e não sobre abstrações” ${ }^{10}$. Nesse marco, Sólon foi um protagonista sagaz que teve a virtude de libertar sua ação do mero interesse pessoal.

Sólon consegue, em primeiro lugar, desativar um levante de camponeses ao eliminar os pesados impostos que deviam pagar para a aristocracia. A delicada situação financeira do campesinato levava muitos deles inexoravelmente à escravidão ante a impossibilidade de pagar suas dívidas. Resume a situação de maneira brilhante: "é a própria natureza da riqueza não ter nem objetivo nem medida". Logo rechaça a tentação de se transformar em tirano dos camponeses ${ }^{11}$ e, finalmente, codifica a normativa que regulava a vida na Polis, que até esse momento estava regida por uma mescla de discricionalidade, costume e direito divino.

Há que reconhecer nesse contexto que, para Sólon, o sentido da justiça obedece a uma concepção moral e religiosa. Não devemos interpretar que o ordenamento social proposto derivava exclusivamente da razão especulativa, seu ideal jurídico está vinculado à tradição, o que há de novo é a vontade de ordenar a Polis sobre a base da Lei.

Esta última era concebida pelos gregos como uma muralha da contenção contra toda forma de falta de comedimento e entendida como uma proteção contra o despotismo dos governantes pois punha limites à pleinexia - avidez desmedida de riqueza e de poder de certos cidadãos.

Desta maneira, fica aberto o caminho para a segunda grande transformação: a Democracia. Esse sistema de governo, patrimônio de Atenas no momento de seu máximo esplendor, continua sendo modelo de referência e fonte de inspiração para o desenvolvimento das teorias políticas modernas.

C. A Democracia. “...Pelo fato de nosso Estado ser administrado no interesse do povo e não de uma minoria, nosso regime tomou o nome de Democracia”... "cada um obtém reconhecimento em função do mérito, a classe à qual pertence importa menos que seu valor pessoal” ${ }^{12}$. 
O sinoecismo implicou, no caso particular de Atenas ${ }^{13}$, além da unificação dos distintos povoados em uma Polis e a mudança na concepção da justiça, uma lenta transformação política na qual se foi limitando paulatinamente o poder do rei. Primeiro o rei foi controlado por um tribunal aristocrático, em seguida este conselho foi dividido em três magistrados eleitos e com duração limitada a um ano. Esse grande processo não esteve isento de tensões entre os particularismos regionais e de rivalidades entre as distintas famílias aristocráticas que representavam as antigas aldeias.

Como foi assinalado, Sólon, ao promulgar uma série de leis que foram tornadas públicas, limita definitivamente a autoridade da aristocracia governante, cria um direito comum para todos os atenienses e faz triunfar a concepção segundo a qual a Lei possuía superioridade decisiva sobre os Diké. Dessa maneira, fica aberto o caminho para uma nova forma de sociedade política que, por sua própria natureza, despertava a aspiração de igualdade e de maior participação.

Foi quase um século depois que Atenas se transformou em uma cidade democrática. Clístenes, no ano de 508 antes de Cristo, guiado pelo princípio da isonomia (igualdade), rompe com a organização anterior ligada às famílias ou clãs e instaura um regime baseado na igualdade de todos os cidadãos.

O novo Conselho formado segundo critérios matemáticos de proporcionalidade, no qual não há senão cidadãos iguais entre si, davam a Clístenes uma esmagadora maioria democrática no corpo colegiado. Desse modo, se aumenta a quantidade de cidadãos ao incorporar um importante número de $\operatorname{metecos}^{14}$, e se abrem as outras magistraturas a qualquer cidadão ateniense. Sua eleição ficou confiada ao que surgisse de um sorteio entre todos os cidadãos, sem exclusões ou preferências.

O objetivo de Clístenes foi destruir o poder político da nobreza que, comandada por Iságoras e apoiada pelas tropas de Esparta ${ }^{15}$, buscou impor um regime aristocrático.

Dessa maneira, a idéia de igualdade supera uma nova etapa ao considerar que todos os cidadãos são iguais. A existência de excluídos - mulheres, escravos, estrangeiros - não tira a significado do fato. Cabe recordar que Roma, em escala imperial, atribui a igualdade a todos os cidadãos com o "Edito de Caracalla” no ano de 212 depois de Cristo e que no ocidente, o princípio de igualdade entre os homens, mesmo tendo sido sustentado pelo cristianismo desde seu início no plano religioso, só foi aceito recentemente com o conceito de direitos humanos.

Péricles - o guardião da democracia - foi quem dirigiu Atenas no momento de seu máximo esplendor. A coisa pública se transforma na ocupação favorita do Demos e os negócios da Polis, em um assunto que interessa a todos e a cada um. Ser cidadão se transforma, então, em uma atividade remunerada.

Como destacou o próprio Péricles: "a pobreza não deve ter como efeito que um homem seja impedido de prestar serviço ao Estado...o homem que 
não participa de forma alguma deve ser considerado como acomodado, se não como inútil”.

Uma das principais reformas levadas a cabo por Péricles foi a de eleger os Arcontes mediante o sorteio entre todos os cidadãos e a de limitar os poderes do Areópago à jurisdição nos assuntos criminal e no religioso. É indubitável que através dessas medidas ele buscou aumentar seu próprio poder, mas é certo também que tais medidas foram aceitas porque respondiam ao princípio da isonomia.

Desse modo, a Democracia de Atenas se caracterizava pela transparência. Os políticos se organizavam em praça pública (Ágora) onde os cidadãos eram os juizes do aberto choque de idéias. A Ágora se constitui no centro político da Polis, lugar onde se opunham os que aspiravam comandar o Demos. Dessa maneira, o poder político perde seu caráter privado, secreto e inacessível. A Ágora permitiu inclusive os questionamentos críticos mais agudos a respeito da lei, da democracia e do valor da palavra, quer dizer, de todos os elementos essenciais sobre os quais se sustentava a concepção da antigüidade grega clássica. Tais questionamentos marcaram de maneira profunda o pensamento político e filosófico do ocidente.

Como resume de maneira brilhante J. P. Vernant ${ }^{16}$ "no lugar do rei, cujo controle se exercia sem controle e sem limite, na obscuridade do secreto de seu palácio, a vida política grega é objeto do debate público, que se realiza na claridade da Ágora, por cidadãos que se definem como iguais e para os quais o Estado é um assunto comum”. O que distinguia a Polis era que a Lei, expressão da vontade do Demos, era o único Rei Todo Poderoso.

No século quinto antes de Cristo, Atenas se transforma no cabeça de uma grande anfictionia ${ }^{17}$ marítima que reconhecia Delos como centro religioso e a democracia como elemento de coesão ideológica. Péricles aprofunda a unidade em torno da Liga de Delos liderada hegemonicamente por Atenas. Mas a derrota de Atenas na Guerra do Peloponeso, no ano 404 antes de Cristo, abre a porta para um período de desmoralização, de instabilidade política e de forte crítica ao sistema democrático ateniense.

D. A Liberdade. "Nós ajudamos o povo, fazemos a guerra ao despotismo, consideramos como grande dor que a maioria seja submetida à vontade de uns poucos” ${ }^{18}$.

É possível recordar que anteriormente ao desenvolvimento da democracia em Atenas, os gregos se multiplicaram em uma grande quantidade de repúblicas vulneráveis à ameaça externa, o que os levou à formação de confederações (anfictionias) unidas sobre a base da religião comum. A influência de Delfos, o santuário de Apolo, se fez sentir na sustentação da idéia de uma unidade nacional que subjazia como fundo religioso comum no pensamento da aristocracia grega. 
Como assinalou Rubén Calderón Bouchet: “a fé comum no panteão helênico erigiu-se acima dos interesses dos clãs - a unidade espiritual da Grécia - e essa fé comum teve uma expressão institucional no oráculo de Delfos”... “A decadência da nobreza fez perder a fé, a base tangível de sua realização. O oráculo de Delfos e a unidade nacional não sobreviveram a essa perda”.

Sem embargo, inclusive durante o período grego clássico, caracterizado pela concepção da "cidade-Estado", existia entre os gregos um sentimento de solidariedade helênica, uma concepção de comunidade grega que unia o mundo grego. A ameaça externa da Pérsia reviveu as forças que a impeliam em direção à nação.

As Guerras Médicas, desencadeadas pelo levantamento contra a dominação persa (499 antes de Cristo) e a intervenção em Atenas em favor dos subordinados, são o catalisador decisivo para esse despertar da consciência helênica.

Ao enfrentar a ameaça persa, os gregos expressam a vontade de formar uma unidade cultural. Nesse contexto, a língua comum era, sem dúvida, um dos principais elementos unificadores de seu mundo, independentemente das múltiplas variações regionais, uma vez que servia para transmitir sua cultura e para diferenciálos dos povos bárbaros.

Sem embargo, os limites do mundo grego estavam mal definidos, a dispersão das pequenas colônias em todo o mediterrâneo e a própria geografia da Grécia, ao dificultar a comunicação, eram elementos que não favoreciam a união entre os gregos. Havia, entretanto, algo além da geografia e da dispersão que explica o fracasso das diferentes tentativas de unificação grega. Esse algo mais estava intimamente ligado à concepção política da Polis. Como explica Jean Touchard: "as alianças militares não lograram jamais tomar forma política. Os gregos se uniram para defender sua liberdade contra os bárbaros, mas essa busca de liberdade constituía o limite de todas suas concepções recíprocas”19. O marco da Polis era sentido como um ideal insubstituível. As propostas imperialistas ou hegemônicas geradas pelas guerras foram, no fundo, sempre consideradas como anomalias que deviam ser superadas.

Ninguém, nem mesmo aqueles que propunham com maior entusiasmo a paz e a unidade entre as cidades gregas e uma aliança contra invasores externos, sugeria a idéia de uma integração política entre as diferentes Polis. A aspiração de liberdade e de tolerância foi um dos legados mais importantes que o mundo grego deixou para a cultura ocidental. Devemos o ideal de unidade política debaixo de uma autoridade central - geradora de justiça e protetora da liberdade individual - ao mundo romano ${ }^{20}$.

Na concepção da Polis como unidade completa e independente se percebia a preocupação grega pelo equilíbrio e a harmonia, para evitar a falta de comedimento da hybris em qualquer de suas formas. Como destaca Marcel Prelot: “os gregos não concebiam vastos Estados como os de hoje em dia, nem a geografia do país, 
nem o gosto pelas proporções e pela medida se acomodariam a grandes dimensões" ${ }^{21}$. Por exemplo, Hipodomo de Mileto, o grande arquiteto e humanista, queria limitar a cidade ideal a 10.000 cidadãos. Aristóteles também recomendava que a Polis não fosse nem demasiado grande nem demasiado povoada, nessa busca do equilíbrio harmonioso no qual todos os elementos deviam guardar relação ${ }^{22}$.

Cabe destacar que os gregos já tinham claro o custo econômico da autonomia. A integração implica, inexoravelmente, que algumas das decisões deixem de ser tomadas dentro da Polis. É por isso que Aristóteles propunha que os cidadãos deviam aceitar uma vida frugal ${ }^{23}$.

Como anteriormente assinalado, Péricles (495-529 a.C.) tentou a unificação dos gregos sob a liderança espiritual e intelectual de Atenas, mas ele fracassa ante a oposição de Esparta. As guerras do Peloponeso acabam com esse sonho, tendo Atenas sofrido uma derrota total ${ }^{24}$.

Nos séculos IV e III a.C., posteriormente à derrota de Atenas ante Esparta e simultaneamente a fortes transformações econômicas ${ }^{25}$, surgem no mundo grego escolas de pensamento que questionavam sobre os fundamentos que sustentavam a Polis. Por um lado, sofistas questionavam elementos essenciais dessa sociedade política, relativizavam o valor das leis, argumentavam que muitas vezes elas contrariavam a justiça. Por outro lado, o cinismo, doutrina de contracultura, debilitava o dogma da excelência da Polis ao defender, no marco de um moralismo individualista ascético, aberto a um certo cosmopolitismo, o objetivo de libertar-se das paixões, das necessidades físicas e, fundamentalmente, da vida social.

Nesse contexto de questionamentos, merece ser destacada a figura de Sócrates, que não somente critica o sistema democrático ateniense como lança dúvidas sobre a existência dos deuses da cidade. É por esse motivo que ele é levado a juízo debaixo da acusação de blasfêmia. Para os gregos clássicos, a liberdade se limitava ao direito de participar no governo da cidade, não chegava ao direito de buscar objetivos pessoais, os direitos individuais eram desconhecidos ${ }^{26}$.

De menor transcendência filosófica, foi Isócrates (436-338 antes de Cristo) quem, evidentemente influenciado pela obra de Péricles, tenta novamente impulsionar as idéias do Pan-helenismo. Isócrates assinalava a necessidade de formar uma confederação grega para defender-se ${ }^{27}$ do mundo bárbaro e para proteger a identidade grega, entendida sob critérios mais amplos ${ }^{28}$. Desse modo, destacava os custos dos enfrentamentos dentro do mundo helênico e dos benefícios da paz para o desenvolvimento do comércio e da atividade econômica.

Isócrates, sem sabê-lo, já utilizava, para justificar a integração entre os gregos, as três categorias explicativas da teoria realista nas Relações Internacionais, a saber: a segurança, a identidade nacional e a prosperidade.

Cabe destacar que, em princípio, Isócrates desenvolve a idéia do panhelenismo pensando que Atenas teria o papel central em um processo que conduziria a uma nova entidade que não seria somente ateniense mas grega. No entanto, 
paulatinamente, ao constatar as dificuldades que se opunham à unificação e o egoísmo "nacional" ateniense, busca fora do mundo grego um chefe, o hegemon que poderia liderar o desejado pan-helenismo. Filipe da Macedônia parecia contar com a força e a grandeza necessárias para transformar-se no homem providencial que alcançaria tal objetivo.

O raciocínio de Isócrates o levava a pensar que, ainda que governados sob um sistema político diametralmente oposto ao de Atenas, os macedônios não eram um povo estranho, faziam parte da cultura helênica. Ele entendia que os macedônios forjariam a união no marco do respeito das concepções políticas atenienses. O que Isócrates não podia prever era que suas idéias, livres de todo interesse pessoal, iam favorecer a destruição do mundo grego clássico, de sua concepção da Polis e da democracia. Sem dúvida seus argumentos debilitaram a posição daqueles que, liderados por Demóstenes, viam com extrema desconfiança os hábeis movimentos do Rei Filipe. Este último, pacientemente isolou Atenas de outras democracias gregas por um lado, e, por outro, fortaleceu seu vínculos com as cidades oligárquicas, colocando a Macedônia em uma posição central no tabuleiro internacional do mundo grego.

Finalmente, Filipe da Macedônia - aquele a quem Isócrates queria transformar no herói da causa do helenismo - desmascara seu jogo e impõe a “integração" do mundo grego de fora para dentro. As forças democráticas lideradas por Atenas são destruídas na batalha de Queronéia no ano de 338 antes de Cristo.

Pouco depois, Filipe da Macedônia, para preservar as formas, se faz nomear hegemon da Liga de Corinto. Essa liga ocultava muito tenuamente, debaixo de uma suposta estrutura federal ${ }^{29}$, a realidade de ser um mero instrumento de poder do Rei. Desse modo, Filipe obriga todas as cidades gregas a jurar uma "paz comum entre os gregos” e a ajudar-se contra todo inimigo. Trata-se de uma aliança militar, sob a hegemonia da Macedônia com vistas a uma guerra de expansão contra os Persas.

Dessa maneira, Filipe da Macedônia consegue transformar em realidade a aspiração da unidade e paz de Isócrates. Ao mesmo tempo, no entanto, destrói a autonomia das cidades gregas e, mais fundamentalmente, a concepção política democrática sobre a qual a Polis ateniense se sustentava. Fica aberta, assim, a porta para a fugaz e transcendente expansão do mundo helênico, sob a forma imperial e liderada por outro hegemon: Alexandre.

No que respeita a Isócrates, o tímido professor de retórica de voz débil mas de poderosas idéias, se deixa morrer de fome ao ver que a unidade e a paz helênicas serão forjadas pela violência, que conduz de maneira inexorável a silenciar a Ágora. 


\section{Notas}

1 SCHOOYANS, Michel. Syllabus de Philosophie politique. Bruxelles: UCL, 1990, p. 4.

2 FINLEY, M.I. Os Gregos Antigos Lisboa: Edições 70, 1970.

RACHET, G. et M. F. Dictionnaire de la Civilisation Grecque. Paris: Larousse, 1990, p. 71. CRAHAY, Roland. La Religion des Grecs. Bruxelles: Éd. Complexe, 1991, p. 112.

5 Ainda que não invalide a linha de pensamento, cabe declarar que a Polis era uma comunidade exclusiva em muitos sentidos. A maioria, excluída de todas participação política eram os "nãocidadãos” que poderiam classificar-se em três grandes grupos: os “metecos” - gregos e estrangeiros que viviam por gerações na Polis como homens livres sem alcançar a cidadania - as mulheres e os escravos.

6 Tradução livre de uma reflexão de Hieráclito, extraída do livro de Dominique Colas. La Pensée Politique. Larousse: Paris, 1992, p. 19.

7 CRAHAY, Roland. opus cit. p. 111.

8 SCHOOYANS, Michel. opus cit. pp. 5 e 6.

9 O austero Sólon, nascido de uma família nobre, renega sua herança para enriquecer-se na experiência de várias viagens. Logo se faz célebre recitando suas poesias de forte conteúdo "político e social” na Ágora. Talvez, o mais célebre de seus poemas tenha sido precisamente "Eunomia". Ver a respeito Marcel Humbert, Institutions politiques et sociales de l'antiquité. Paris: Precis Dalloz, 1991.

10 BOUCHET, Rubén Calderón. La Ciudad Griega, Buenos Aires: Ciudad Argentina, 1998, p. 162.

11 MOSSÉ, Claude. Histoire d'une démocratie: Athènes. Paris: Editions du Seuil, 1971, pp. 15-18.

12 Extrato de um discurso de Péricles publicado no livro: MOSSÉ, Claude. opus cit p. 47.

13 Cabe esclarecer que nem todas as Polis desembocaram em sistemas da governos democráticos.

14 Gregos e estrangeiros livres mas que não eram cidadãos.

15 Essa situação favoreceu o desenvolvimento de um sentimento nacionalista no povo de Atenas que foi explorado por Clístenes.

16 VERANT, Jean Pierre. Les origines de la pensée grecque. Paris: Presse Universitaires de France, 1990, p. 7.

17 Anfictionias poderia ser traduzida como confederações. A palavra deriva da lenda que diz ter sido Anfiction o primeiro a formar uma liga de Estados com o propósito de unir-se para a defesa mútua ante um perigo externo.

18 Isócrates, tradução livre baseada na citação de PRELOT, Marcel \& LESCUYER, Georges. Histoire des idées politiques. Paris: Dalloz, 1990, p. 53.

19 TOUCHARD, Jean. Histoire des Idées Politiques. Tome I. Paris: Presse Universitaires de France, 1990, p. 44.

20 HAINES, C. Grove \& WALSH, Warren B. The Development of Western Civilization. New York: Syracuse University, 1947.

21 PRELOT, Marcel \& LESCUYER, Georges. Histoire des Idées Politiques. Paris: Dalloz, 1990, p. 38.

22 Idem. p. 131.

23 MATTLI, Walter. The Logic of Regional Integration. Cambridge: Cambridge University Press, 1999, p. 57.

24 A Guerra do Peloponeso, 431-404 antes de Cristo, marca o fim do império ateniense.

25 Cabe destacar que nesse período se regenera um importante desenvolvimento econômicocomercial na cidade de Atenas. Os metecos, estrangeiros autorizados a viver na cidade, controlavam em grande medida esse comércio. A paulatina mas crescente participação dos 
cidadãos atenienses na busca de benefícios gerados pelo comércio e outras atividades econômicas era objeto de forte crítica à luz das concepções morais da Grécia clássica.

\section{GRESS, David. From Plato to Nato. New York: The Free Press, 1998, pp. 86-94.}

Na realidade propunha desviar a energia dos gregos, concentrada na luta entre si, a fim de canalizá-la para uma luta de conquista que permitiria aos gregos contar com novas riquezas e terras férteis para emigração. FINLEY, M. I. Os Gregos Antigos. Lisboa: Edições 70, 1970. Cabe destacar que Isócrates (influenciado pelo pensamento sofista, que sustentava a preponderância da cultura sobre a natureza) defendia a idéia de que "são gregos aqueles que compartilham nossa educação, mais que aqueles que têm nossa mesma origem.” PRÉAUX, Claire. Le monde hellenistique. Tome II. Paris: Presses Universitaire de France, pp. 545-550. A liga estava dominada por um conselho federal denominado sinedron, que representava todas as cidades na proporção da população e um hegemon. 